\title{
Does Coronavirus Disease Affect Sleep Disorders in the Third Trimester of Pregnancy in Women With Low Back Pain?
}

\author{
Roghayeh Dargahi $^{1}{ }^{\circledR}$, Behrooz Nazari $^{2}$, Abbasali Dorosti ${ }^{3}$, Saeid Charsouei ${ }^{* * \mathbb{C}}$
}

\begin{abstract}
Objectives: Many factors such as stress and psychological tension affect the mental and physical health of pregnant women in the third trimester during the coronavirus pandemic. These factors can cause severe complications such as sleep disorders and low back pain. Therefore, this study focused on investigating sleep disorders in women by diagnosing low back pain in pregnant women with coronavirus and the affecting factors.

Materials and Methods: This descriptive-analytical study was performed during the four months ending July 5, 2020 with the participation of 40 pregnant women (with coronavirus disease detected in the last trimester of pregnancy) with a diagnosis of low back pain in Tabriz (Iran) using a random sampling technique. Demographic data, anxiety and depression, Petersburg's sleep quality, factors affecting sleep quality, and the severity of back pain (visual analog scale) were electronically collected and analyzed using SPSS 20 by ANOVA and multivariate regression.

Results: All participants were at a weak level. The majority of participants had a score of "serious sleep problem", and nausea and vomiting $(P=0.041)$, low back pain $(P=0.003)$, frequent urination $(P=0.011)$, leg cramps $(P=0.031)$, and constipation $(P=0.018)$ caused severe sleep disturbance in pregnant women during coronavirus pandemic.

Conclusions: In general, having coronavirus disease causes severe pain in pregnant women, leading to severe back pain in pregnancy, eventually worsening sleep disorders.

Keywords: Sleep disorder, Pregnancy, Low back pain pregnancy, Coronavirus, Third trimester
\end{abstract}

\section{Introduction}

Pregnancy is one of the most important periods in the life of every woman, which is a highly stressful period due to many physical and psychological changes accompanying it (1). The most common problem of this period is low back pain in pregnancy, which increases by increasing gestational age so that its prevalence increases from 33\% in the first trimester to $94 \%$ and $97 \%$ in the second and third trimesters, respectively (2).

Hormonal changes during pregnancy directly affect the sleep-wake cycle and sleep structure. Estrogen and progesterone are the hormones associated with sleep homeostasis and their concentration increase during pregnancy causes some changes in sleep patterns. In addition, physical and mechanical factors can affect the quality of sleep during pregnancy, including fetal growth, uterine contractions, low back pain, fetal movement, abdominal pain, frequent urination, foot cramps, and gastroesophageal reflux disease, and some emotional factors such as fear of new experiences and acceptance of new roles $(3,4)$. Low back pain during pregnancy (70\% prevalence) can be a major cause of sleep disorders in pregnancy (5). The coexistence of low back pain in pregnancy with sleep disorders has caused various problems so that some pregnant women are not willing to become pregnant again, indicating the intolerance of these two complications together (6). Coronavirus disease 2019 (COVID-19) leads to chronic and extremely severe pain (7), and many factors such as stress and psychological stress posed on pregnant women with COVID-19 affect their mental and physical health in the third trimester, causing more severe complications such as sleep disorders and low back pain. In this regard, the present study evaluated sleep disorders in women by diagnosing low back pain in pregnant women with coronavirus and the contributing factors.

\section{Materials and Methods}

Study Design

This descriptive-analytical study was conducted on pregnant women (with COVID-19) with medical records in educational and health centers in Tabriz (Iran) from March 5, 2020 to July 5, 2020. The minimum sample size was calculated according to the results of a similar study 
Key Messages

- Many women experience sleep disorders during pregnancy.

- Back pain aggravates sleep disorders.

- Stressful conditions lead to worsening sleep disorders and low back pain.

- The pain of COVID-19can make back pain in pregnancy more severe.

(6) and those of the pilot study. The sample size was estimated to be 35 people based on the results of the pilot study, the correlation coefficient of -0.43 between low back pain and sleep quality, the minimum test power of $80 \%$, and a confidence interval of $95 \%$. Due to the possibility of sample loss, $10 \%$ was added to the predicted sample volume (40 people).

For sample selection, the researcher studied the health records of pregnant women and included women with low back pain in pregnancy after obtaining their informed consent by telephone. Cases were randomly selected (eligible files are included in https://www.randomizer.org) and entered into the study.

The study included over 18-years-old, pregnant women in the third trimester, diagnosed with low back pain with at least the literacy, level of diploma, and pregnant women diagnosed with coronavirus having completed treatment. It should be noted that given that patients with coronavirus continue to suffer from pain for a long time after treatment, pregnant women having completed the course of treatment were included in the study. Medications prescribed by an infectious disease specialist for the treatment or control of coronavirus symptoms were given to all patients. Medication was based on the physician's accurate knowledge of the pregnancy. In other words, researchers in this study were unaware of the type of received treatment. Moreover, women were excluded if they received psychiatric medication due to psychological problems and had a history of drug use, alcohol consumption, lumbar disc surgery, previous nonpregnancy low back pain, pre-pregnancy sleeping pills, and prolactin hormone disorder. Further, other exclusion criteria were a history of the good disorder based on sonomammography diagnosis, pulmonary problems, sleep apnea, and working women who had night shifts at least three times a week.

Medications prescribed for pregnant women with COVID-19 were prescribed by their doctors, including low-dose azithromycin, low-dose naproxen, and loratadine tablets. Pregnant women were advised to take these medications if their symptoms were severe.

\section{Tools}

1. Demographic characteristics: It includes age, previous delivery, unwanted mood, and the body mass index (BMI).

2. Dash anxiety tool: It is employed to measure the level of anxiety and depression in pregnant women. The obtained score shows the level of depression and anxiety (each person's final score was 100 (8).

3. Petersburg Sleep Quality Questionnaire: This questionnaire has 19 items scored on a 4-point Likert-type scale from zero to three. It has 7 subscales including the mental quality of sleep, delay in falling asleep, sleep duration, sleep efficiency, sleep disorders, use of sleeping pills, and daily functional disorders. A higher score represents the lower quality of sleep and a score higher than 5 indicates a disturbance in sleep quality. It should be noted that the use of sleeping pills was not questioned during pregnancy $(3,9)$.

4. The researcher-made form: It measures factors affecting sleep disorders, including nausea, vomiting, headache, excessive sleep and fatigue, heartburn, leg cramps, bloating, constipation, frequent urination, and inactivity during the day.

5. Tools for low back pain severity: The visual analog scale was used to determine the severity of low back pain. The scores were divided into four categories demonstrating mild (A score of $<20$ ), moderate (2040 ), severe (a score of 40-60), and excruciating (a score of $>60$ ) pain where the patient needs to visit a doctor and take medication (9).

\section{Methodology}

First, the researchers assured the participants' satisfaction in the study by telephone and then sent relevant forms to each person via email or telegram. The researcher reviewed the medical records of pregnant women who had completed a full course of treatment for coronavirus while not reviewing cases who showed incomplete intake of coronavirus control drugs. Each person was told to choose only one option for each question, and if they had a problem, they should not send the form so that the researcher could contact them and solve the problem. Furthermore, researchers attempted to make the number of people who enter each group proportional so that all groups had equal weight and their information was easily compared while considering that the size of the groups was approximately the same.; On the other hand, to evaluate the main variables, it was sought to match patients' initial variables so that only the main variables were examined and their effects were determined in this study.

\section{Statistical Analyses}

Relevant forms were completed online by each person. The incomplete data were resubmitted for each patient. Then, the data were entered into SPSS 20, and descriptive statistics (i.e., number, percentage, mean, and standard deviation), as well as analysis of variance (ANOVA) and chi-square tests were used to present and analyze the data, respectively. 


\section{Results}

The mean \pm SD age and BMI of study participants were $25.19 \pm 03.59$ years and $23.63 \pm 03.40$, respectively. The mean SD scores of anxiety $(63.45 \pm 05.25)$ and depression $(60.50 \pm 05.15)$ also indicated that the level of these two variables was high. Table 1 provides the study of demographic information and the severity of depressive anxiety in women participating in the study by the seventh, eighth, and last months.

The mean \pm SD of the sleep quality score of the participants was $12.15 \pm 02.80$, indicating that the sleep quality of the study participants was low. A comparison of sleep quality of each month demonstrated that sleep quality deteriorated insignificantly. The status of sleep quality subscales also indicated that the sleep quality decreases non-significantly $(P<0.05)$ in all subscales the closer we get to the time of delivery (Table 2). On the other hand, the study of low back pain intensity represented that the mean \pm SD of total pain intensity was $50.55 \pm 10.75$. Based on the comparison of pain intensity in different months, pain intensity increased non-significantly with the approach of labor $(P<0.05)$. Moreover, the examination of the low back pain severity scales revealed that pain intensity in all its dimensions significantly increased with the length of pregnancy $(P<0.05)$. The frequency distribution of the research units according to the possible causes of sleep disorders showed that back pain (40\%-100\%), leg cramps (35\%-87.50\%), frequent urination (31\%-77.50\%), headache (29\%-72.50\%), and constipation (28\%-70.00\%) had the highest frequency (Table 2).

The distribution of participants based on sleep scores indicated that all participants were at a poor level (scoring more than 5 based on the relevant scale). On the other hand, the majority of participants scored "severe sleep problem" (scoring more than 2 based on the relevant scale) in all surveyed areas. Table 3 presents the evaluation of good quality and its areas in the study participants separately for each month.

The results of the multivariate regression test represented that low back pain, frequent urination, and leg cramps with sleep disorders were among the possible causes of sleep disorders. More precisely, nausea and vomiting

Table 1. Demographic Characteristics and Severity of Anxiety and Depression in Women With Third Trimester Pregnancy With Low Back Pain of Pregnancy Participating in the Study

\begin{tabular}{|c|c|c|c|c|c|}
\hline \multirow{2}{*}{ Variable } & & \multicolumn{3}{|c|}{ Participants $(\mathrm{N}=40)$} & \multirow{2}{*}{$P$ Value $^{\mathrm{a}}$} \\
\hline & & Seventh Month $\mathrm{n}=12(\%)$ & Eighth Month $\mathrm{n}=17(\%)$ & Last Month $n=11(\%)$ & \\
\hline \multirow{6}{*}{ Age } & Mean \pm SD & $24.85 \pm 03.41$ & $25.45 \pm 03.19$ & $25.93 \pm 03.92$ & \multirow[t]{3}{*}{0.119} \\
\hline & Under 18 years & $4-33.33$ & $6-35.29 \%$ & $4-36.36 \%$ & \\
\hline & 20 to 25 years & $4-33.33$ & $5-29.41 \%$ & $3-24.27 \%$ & \\
\hline & 25 to 30 years & $2-16.66$ & $4-23.52 \%$ & $2-18.18 \%$ & \multirow[t]{3}{*}{0.091} \\
\hline & 30 to 35 years & $2-16.66$ & $1-05.88 \%$ & $1-09.09 \%$ & \\
\hline & More than 35 years & $0-00.00$ & $1-05.88 \%$ & $1-09.09 \%$ & \\
\hline \multirow{5}{*}{ BMI } & Mean \pm SD & $22.95 \pm 03.10$ & $23.75 \pm 03.55$ & $23.95 \pm 03.65$ & \multirow[t]{2}{*}{0.203} \\
\hline & Less than normal & $4-33.33$ & $5-29.41$ & $3-27.27$ & \\
\hline & Normal & $5-41.66$ & $7-41.17$ & $4-36.36$ & \multirow{3}{*}{0.088} \\
\hline & Overweight & $2-16.66$ & $3-17.64$ & $2-18.19$ & \\
\hline & Obese & $1-8.33$ & $2-11.76$ & $2-18.18$ & \\
\hline \multirow{2}{*}{$\begin{array}{l}\text { Previous } \\
\text { delivery }\end{array}$} & Yes & $4-33.33$ & $6-35.29$ & $3-27.27$ & \multirow{2}{*}{0.519} \\
\hline & No & $8-66.66$ & $11-64.70$ & $8-72.72$ & \\
\hline \multirow{2}{*}{$\begin{array}{l}\text { Unwanted } \\
\text { pregnancy }\end{array}$} & Yes & $4-33.33$ & $4-23.52$ & $3-27.27$ & \multirow{2}{*}{0.356} \\
\hline & No & $8-66.66$ & $13-76.47$ & $8-72.72$ & \\
\hline \multirow{2}{*}{ Diabetes } & Yes & $3-25.00$ & $4-23.52$ & $2-18.18$ & \\
\hline & No & $9-75.00$ & $13-76.48$ & 9-81.81 & \\
\hline \multirow{5}{*}{ Anxiety } & Mean \pm SD & $58.95 \pm 05.50$ & $60.15 \pm 05.45$ & $64.18 \pm 05.80$ & 0.079 \\
\hline & Normal & $1-08.33$ & $0-00.00$ & $0-00.00$ & \multirow{4}{*}{0.479} \\
\hline & Mild & $4-33.33$ & $7-41.17$ & $3-27.27$ & \\
\hline & Severe & $5-41.66$ & $9-52.94$ & $6-54.54$ & \\
\hline & Highly intense & $2-16.66$ & $1-05.88$ & $2-18.18$ & \\
\hline \multirow{5}{*}{ Depression } & Mean \pm SD & $58.45 \pm 04.95$ & $60.15 \pm 05.45$ & $62.50 \pm 05.45$ & 0.103 \\
\hline & Normal & $1-08.00$ & $2-11.76$ & 1-09.09 & \multirow{4}{*}{0.563} \\
\hline & Mild & $4-33.33$ & $4-23.52$ & $4-36.36$ & \\
\hline & Severe & $5-41.66$ & $8-47.05$ & $3-27.27$ & \\
\hline & Highly intense & $2-16.66$ & $3-17.64$ & $3-27.27$ & \\
\hline
\end{tabular}

Note. SD: Standard deviation; BMI: Body mass index;

${ }^{a}$ Analysis of variance (ANOVA). 
Table 2. Comparison of Sleep Quality in Women With Third-trimester Pregnancy With a Diagnosis of Low Back Pain and Causes of Sleep Disorders

\begin{tabular}{|c|c|c|c|c|c|}
\hline \multirow{2}{*}{ Variable } & \multicolumn{4}{|c|}{ Participants $(\mathrm{N}=40)$} & \multirow{2}{*}{$P$ Value $^{\mathrm{a}}$} \\
\hline & Seventh Month $(n=12)$ & Eighth Month $(n=17)$ & Last Month $(\mathrm{n}=11)$ & Total $(n=40)$ & \\
\hline \multicolumn{6}{|c|}{ Sleep Quality } \\
\hline Total & $10.20 \pm 02.45$ & $11.45 \pm 02.25$ & $13.10 \pm 02.85$ & $12.15 \pm 02.80$ & 0.209 \\
\hline Mental quality of sleep & $0.65 \pm 0.25$ & $0.72 \pm 0.30$ & $0.91 \pm 0.45$ & $0.85 \pm 0.41$ & 0.103 \\
\hline Delay in falling asleep & $1.01 \pm 0.15$ & $1.20 \pm 0.40$ & $1.55 \pm 0.45$ & $1.36 \pm 0.15$ & 0.083 \\
\hline Sleep time & $6.45 \pm 1.10$ & $7.10 \pm 1.20$ & $7.95 \pm 1.85$ & $7.62 \pm 1.45$ & 0.115 \\
\hline Sleep efficiency & $0.15 \pm 0.02$ & $0.18 \pm 0.05$ & $0.25 \pm 0.06$ & $0.21 \pm 0.05$ & 0.085 \\
\hline Sleep disorders & $1.10 \pm 0.41$ & $1.15 \pm 0.49$ & $1.29 \pm 0.71$ & $1.25 \pm 0.59$ & 0.285 \\
\hline Daily functional disorders & $0.55 \pm 0.07$ & $0.63 \pm 0.11$ & $0.71 \pm 0.15$ & $0.69 \pm 0.12$ & 0.119 \\
\hline \multicolumn{6}{|c|}{ Back Pain } \\
\hline Total & $45.15 \pm 10.25$ & $48.30 \pm 10.10$ & $52.50 \pm 11.35$ & $50.55 \pm 10.75$ & 0.115 \\
\hline Mild & $13.15 \pm 03.10$ & $15.45 \pm 03.85$ & $17.25 \pm 04.10$ & $15.10 \pm 03.40$ & 0.119 \\
\hline Medium & $32.55 \pm 05.10$ & $35.50 \pm 05.05$ & $38.10 \pm 05.40$ & $37.15 \pm 05.15$ & 0.309 \\
\hline Severe & $55.15 \pm 07.10$ & $56.55 \pm 05.40$ & $57.75 \pm 08.10$ & $56.15 \pm 07.25$ & 0.211 \\
\hline \multicolumn{6}{|c|}{ Causes of Sleep Disorders (\%) } \\
\hline Vomiting and nausea & $8-66.66$ & $12-70.58$ & $6-54.54$ & $26-65.00$ & 0.215 \\
\hline Headache & $7-58.33$ & $14-82.35$ & $8-72.72$ & $29-72.50$ & 0.115 \\
\hline Too much sleep and fatigue & $9-75.00$ & $11-64.70$ & $6-54.54$ & $26-65.00$ & 0.329 \\
\hline Heartburn & $3-25.00$ & $5-29.41$ & $3-27.27$ & $11-27.50$ & 0.259 \\
\hline Leg cramps & $8-66.66$ & $17-100.00$ & $10-90.90$ & $35-87.50$ & 0.149 \\
\hline Flatulence & $2-16.66$ & $5-29.6241$ & $2-18.18$ & $9-22.50$ & 0.326 \\
\hline Constipation & $6-50.50$ & $14-82.35$ & $8-72.72$ & $28-70.00$ & 0.145 \\
\hline Frequent urination & $9-75.00$ & $12-70.58$ & $10-90.90$ & $31-77.50$ & 0.211 \\
\hline Inactivity during the day & $6-50.00$ & $8-47.05$ & $3-27.27$ & $17-42.50$ & 0.307 \\
\hline Back pain & $12-100.00$ & $17-100.00$ & $11-100.00$ & $40-100.0$ & 0.257 \\
\hline
\end{tabular}

${ }^{a}$ Analysis of variance (ANOVA).

$(P=0.041)$, low back pain $(P=0.003)$, frequent urination $(P=0.011)$, leg cramps $(P=0.031)$, and constipation $(P=0.018)$ caused severe sleep disorders in pregnant women during the coronavirus pandemic. Further, the mentioned variables predicted sleep disorders in women with low back pain in pregnancy and with COVID-19. The predictors of sleep disorders in women with low back pain in pregnancy with COVID-19 are listed in Table 4.

\section{Discussion}

The aim of the present study was to determine whether COVID-19 conditions can exacerbate sleep disorders in pregnant women in the third trimester of pregnancy by diagnosing low back pain. According to the results, the overall rate of sleep disorders in pregnant women was $100 \%$, which was one of the significant aspects of this study. Although the sleep disorders were high in previous studies $(8,9)$, in the current study, the sleep disorder was present in $100 \%$ of cases as one of the variables which may exacerbate critical and stressful conditions in COVID-19. In addition, this complication may have devastating effects on pregnancy outcomes and neonatal outcomes if pregnant women develop sleep disorders in the last trimester of pregnancy, and these effects will remain on the psychological aspects of postpartum mothers and transfer to the future, causing mental health problems such as stress, sleep disorders, and depression (2).

In a study on the causes of sleep disorders in women with breast cancer, it was proposed that critical and stressful conditions can increase the severity of sleep disorders (9). Therefore, it seems that the critical conditions of the corona pandemic period have led to sleep disorders in pregnant women.

In examining the causes of sleep disorders in the present study, it was found that women with low back pain in pregnancy have more sleep disorders. In other words, low back pain in pregnancy is the main cause of sleep disorders in women in the third trimester of pregnancy. The results of our study are in line with those of similar research (10).

The more pregnant women approach the last days of pregnancy, the more they face movement limitations, leading to more factors such as back pain, and thus sleep disorders and movement limitations during sleep. It can reduce the quality of sleep and have a negative effect on its quality. Additionally, low back pain during pregnancy can affect the results during childbirth through normal or cesarean section $(11,12)$. On the other hand, the stress suffered during the coronavirus pandemic can have a negative effect on the severity of low back pain in pregnancy, which seems to be one of the main reasons 
Table 3. Distribution of Sleep Quality Scores and its Subscales in Different Months of Pregnancy

\begin{tabular}{|c|c|c|c|c|c|}
\hline \multirow[b]{2}{*}{ Variable } & & \multicolumn{3}{|c|}{ Participants $(\mathrm{N}=40)$} & \multirow[b]{2}{*}{$P$ value } \\
\hline & & $\begin{array}{l}\text { Seventh Month } \\
n=12(\%)\end{array}$ & $\begin{array}{c}\text { Eighth Month } \\
n=17(\%)\end{array}$ & $\begin{array}{c}\text { Last Month } \\
\mathrm{n}=11(\%)\end{array}$ & \\
\hline \multirow{2}{*}{ Sleep quality } & Weak & $12-100.00$ & $17-100.00$ & $11-100.00$ & \multirow{2}{*}{0.999} \\
\hline & Normal & $0-00.00$ & 0-00.00 & $0-00.00$ & \\
\hline \multirow{4}{*}{ Mental quality of sleep } & No sleep problems & $1-08.33$ & $2-11.76$ & $0-00.00$ & \multirow{4}{*}{0.117} \\
\hline & Moderate sleep problem & $3-25.00$ & $5-29.41$ & $5-45.45$ & \\
\hline & Serious sleep problem & $5-41.66$ & $6-35.29$ & $5-45.45$ & \\
\hline & Extensively serious sleep problem & $3-25.00$ & 4-23.52 & 1-09.09 & \\
\hline \multirow{4}{*}{ Delay in falling asleep } & No sleep problems & $1-08.33$ & $1-05.88$ & $0-00.00$ & \multirow{4}{*}{0.099} \\
\hline & Moderate sleep problem & $3-25.00$ & $3-17.64$ & $2-18.18$ & \\
\hline & Serious sleep problem & 4-33.33 & $7-41.17$ & $8-72.72$ & \\
\hline & Highly serious sleep problem & $4-33.33$ & $6-35.29$ & $1-09.09$ & \\
\hline \multirow{4}{*}{ Sleep time } & No sleep problems & $1-08.33$ & $2-11.76$ & 1-09.09 & \multirow{4}{*}{0.157} \\
\hline & Moderate sleep problem & $5-41.66$ & $7-41.17$ & $4-36.35$ & \\
\hline & Serious sleep problem & 4-33.33 & $7-41.17$ & $5-45.45$ & \\
\hline & Extremely serious sleep problem & $2-16.66$ & $1-05.88$ & 1-09.09 & \\
\hline \multirow{4}{*}{ Sleep efficiency } & No sleep problems & $2-16.66$ & $2-11.76$ & $0-00.00$ & \multirow{4}{*}{0.149} \\
\hline & Moderate sleep problem & $5-41.33$ & $10-58.82$ & $6-54.54$ & \\
\hline & Serious sleep problem & $3-25.00$ & $4-23.52$ & $5-45.45$ & \\
\hline & Highly serious sleep problem & $2-16.66$ & $1-05.88$ & $1-09.09$ & \\
\hline \multirow{4}{*}{ Sleep disorders } & No sleep problems & $0-00.00$ & $0-00.00$ & $0-00.00$ & \multirow{4}{*}{0.219} \\
\hline & Moderate sleep problem & $3-25.00$ & $6-35.29$ & $6-54.54$ & \\
\hline & Serious sleep problem & $4-33.33$ & $8-47.05$ & $4-36.36$ & \\
\hline & Extremely serious sleep problem & $5-41.33$ & $3-17.64$ & 1-09.09 & \\
\hline \multirow{4}{*}{$\begin{array}{l}\text { Daily functional } \\
\text { disorders }\end{array}$} & No sleep problems & $1-08.33$ & $1-05.88$ & $2-18.19$ & \multirow{4}{*}{0.115} \\
\hline & Moderate sleep problem & $3-25.00$ & $6-35.29$ & $4-36.36$ & \\
\hline & Serious sleep problem & $6-50.00$ & $8-47.05$ & $4-36.36$ & \\
\hline & Highly serious sleep problem & $2-10.52$ & $2-11.76$ & 1-09.09 & \\
\hline
\end{tabular}

${ }^{a}$ Analysis of variance (ANOVA).

for the results of this study. It also seems that severe pain caused by COVID affects back pain during pregnancy and can be one of the reasons that increase the severity of low back pain during pregnancy, which requires more research.

In addition, the results revealed that nausea and vomiting, frequent urination, leg cramps, and constipation have caused severe sleep disorders in pregnant women during the pandemic. In reviewing similar studies, these variables have all been effective on sleep disorders in pregnant women (13-15). Physical changes in the third

Table 4. Investigation of the Relationship Between Sleep Disorder and its Causes in Pregnant Women in the Third Trimester

\begin{tabular}{lll}
\hline Variable & B & $\boldsymbol{P V a l u e}^{\mathbf{a}}$ \\
\hline Vomiting and nausea & 0.039 & 0.041 \\
Headache & 0.315 & 0.219 \\
Too much sleep and fatigue & 0.459 & 0.333 \\
Heartburn & 0.999 & 0.510 \\
Leg cramps & 0.089 & 0.031 \\
Flatulence & 0.895 & 0.589 \\
Constipation & 0.041 & 0.018 \\
Frequent urination & 0.021 & 0.011 \\
Inactivity during the day & 0.502 & 0.201 \\
Back pain & 0.009 & 0.003 \\
\hline
\end{tabular}

${ }^{a}$ Multivariate regression. trimester (e.g., the enlarged uterus, uterine pressure on the bladder and pelvic organs, and pressure on the veins and arteries of the abdomen affecting lower extremities) appear to be among the causes of sleep disorders in pregnant women.

\section{Conclusions}

In general, having COVID causes severe pain in pregnant women, resulting in severe back pain in pregnancy, and eventually worsening sleep disorders.

Limitations of the Study

One of the limitations of this study is the effect of unknown individual factors and other psychological factors of the mother on the quality of women's sleep, which were beyond the control of the researcher. The lack of knowledge about mental disorders probably occurring in pregnant women during the coronary pandemic quarantine period are also factors that could have affected the results of the present study.

Suggestions for Future Studies

The researchers of the present study suggest future studies investigate the role of psychological factors on sleep disorders in pregnant women during the corona pandemic on sleep disorders in addition to determining the share 
of its effect. It is also recommended to conduct training courses through cyberspace to prevent sleep disorders and other psychological problems that have developed following the home quarantine of the corona pandemic period for further studies. The findings of the present study can help obstetricians and neuroscientists identify pregnant women at risk for sleep disorders and low back pain so that to prevent further complications.

\section{Authors' Contribution}

RD: Study design; BN and AD: Data collection; SC: Manuscript writing and submission.

\section{Conflict of Interests}

Authors declare that they have no conflict of interests.

\section{Ethical Issues}

The research project was approved by the Ethics Committee of Tabriz University of Medical Sciences (Ethics no. IR.TBZMED.REC. 1398.1306). The objectives of the research were explained to pregnant women and their husbands' clearance was obtained for the study. It should be noted that researchers had no direct contact with the women, and women could voluntarily participate in the study. The pregnant women agreed on not receiving any fees for this study.

\section{Financial Support}

This study was granted by Tabriz University of Medical Sciences.

\section{Acknowledgments}

The researchers are grateful to the spiritual support provided by Tabriz University of Medical Sciences, as well as the patients who participated in the study.

\section{References}

1. Tsai SY, Lee CN, Wu WW, Landis CA. Sleep hygiene and sleep quality of third-trimester pregnant women. Res Nurs Health. 2016;39(1):57-65. doi:10.1002/nur.21705

2. Karimi FZ, Nosrati Hadiabad SF, Abdollahi M, Karimi L. Frequency of sleep disorders and individual related factors in pregnant women referred to Mashhad health centers in 2019. Iran J Obstet Gynecol Infertil. 2020;23(1):25-32. doi:10.22038/ijogi.2020.15732

3. Sedov ID, Cameron EE, Madigan S, Tomfohr-Madsen LM. Sleep quality during pregnancy: a meta-analysis. Sleep Med Rev. 2018;38:168-176. doi:10.1016/j.smrv.2017.06.005

4. Gao M, Hu J, Yang L, et al. Association of sleep quality during pregnancy with stress and depression: a prospective birth cohort study in China. BMC Pregnancy Childbirth. 2019;19(1):444. doi:10.1186/s12884-019-2583-1
5. Leonel LF, Morelhão PK, Tufik S, Andersen ML. Should health professionals assess sleep quality in pregnant women seeking care for low back pain? J Clin Sleep Med. 2020;16(1):155-156. doi:10.5664/jcsm.8146

6. Rabiee M, Sarchamiee N. Frequency of low back pain in each pregnancy trimester and its related factors in pregnant women visiting Shaheed Mostafa Khomeini hospital in 2015. Iran J Obstet Gynecol Infertil. 2018;20(12):32-39. doi:10.22038/ ijogi.2017.10427

7. Haghdoost SM, Khanbabayi Gol M. The necessity of paying more attention to the neurological and psychological problems caused by COVID-19 pandemic during pregnancy. Int J Womens Health Reprod Sci. 2020;8(3):243-244. doi:10.15296/ijwhr.2020.40

8. Sinesi A, Maxwell M, O'Carroll R, Cheyne H. Anxiety scales used in pregnancy: systematic review. BJPsych Open. 2019;5(1):e5. doi:10.1192/bjo.2018.75

9. Khanbabaei Gol M, Rezvani F, Ghavami Z, Mobaraki-Asl N. Prevalence of neuropathic pain and factors affecting sleep quality in women with breast cancer after radiotherapy. Iran J Obstet Gynecol Infertil. 2019;22(6):46-53. doi:10.22038/ ijogi.2019.13743

10. Silva-Perez LJ, Gonzalez-Cardenas N, Surani S, Etindele Sosso FA, Surani SR. Socioeconomic status in pregnant women and sleep quality during pregnancy. Cureus. 2019;11(11):e6183. doi:10.7759/cureus.6183

11. Aghamohamadi D, Khanbabaei Gol M. An investigation into the effects of magnesium sulfate on the complications of succinylcholine administration in nulliparous women undergoing elective cesarean section: a double-blind clinical trial. Int J Womens Health Reprod Sci. 2019;7(4):520-525. doi: 10.15296/ ijwhr.2019.86.

12. Fakhari S, Bile Jani I, Atashkhouei S, Khanbabayi Gol M, Soliemanzadeh S. Comparing the effect of hypotension treatment due to spinal anesthesia with ephedrine or phenylephrine on arterial blood gases and neonatal Apgar score during cesarean delivery in obese mothers: randomized clinical trial. Iran J Obstet Gynecol Infertil. 2019;22(10):12-20. doi:10.22038/ ijogi.2019.14185

13. Felder JN, Baer RJ, Rand L, Jelliffe-Pawlowski LL, Prather AA. Sleep disorder diagnosis during pregnancy and risk of preterm birth. Obstet Gynecol. 2017;130(3):573-581. doi:10.1097/ aog.0000000000002132

14. Chen SJ, Shi L, Bao YP, et al. Prevalence of restless legs syndrome during pregnancy: a systematic review and meta-analysis. Sleep Med Rev. 2018;40:43-54. doi:10.1016/j.smrv.2017.10.003

15. Li L, Zhao K, Hua J, Li S. Association between sleep-disordered breathing during pregnancy and maternal and fetal outcomes: an updated systematic review and meta-analysis. Front Neurol. 2018;9:91. doi:10.3389/fneur.2018.00091

(C) 2021 The Author(s); This is an open-access article distributed under the terms of the Creative Commons Attribution License (http:// creativecommons.org/licenses/by/4.0), which permits unrestricted use, distribution, and reproduction in any medium, provided the original work is properly cited. 